\title{
Surat Kabar \& Konvergensi Media (Studi Deskriptif Kualitatif Model Konvergensi Media Pada Solopos)
}

\author{
Oleh: Anton Wahyu Prihartono, S.Sos \\ Manajemen Komunikasi Program Pasca Sarjana Universitas Sebelas Maret Surakarta \\ Email: antonwahyup@yahoo.com
}

\begin{abstract}
Abstrak
Perkembangan tekonologi komunikasi saat ini berkembangan sangat pesat. Perkembangan ini juga berpengaruh pada industri media. Media dituntut untuk menyesuaikan dengan perkembangan teknologi komunikasi. Lahirnya media digital yang menggunakan teknologi internet telah mempengaruhi media cetak. Sejumlah media cetak di Amerika Serikat mulai tutup karena tidak mampu bersaing dengan media digital. Media cetak yang saat ini masih bertahan dituntut untuk melakukan konvergensi dengan menyiapkan media-media yang berbasis digital, salah satunya Solopos.

Penelitian ini merupakan penelitian deskriptif kualitatif. Penelitian deskriptif menurut Whitney (dalam Nazir, 1988: 63) yaitu penelitian untuk mencari fakta dengan interpretasi yang tepat. Adapun tujuan dari penelitian ini adalah untuk mengetahui model konvergensi media yang dilakukan Solopos sebagai jawaban atas tuntutan industri media bahwa surat kabar harus mempersiapkan platform digital untuk menghadapi media digital yang terus tumbuh.

Hasil penelitian menunjukkan bahwa Konvergensi media yang dilakukan Solopos merupakan jawaban atas tuntutan industri media bahwa surat kabar harus mempersiapkan platform digital untuk menghadapi media digital yang terus tumbuh.

Model konvergensi media yang dilakukan Solopos adalah model konvergensi newsgathering di mana dalam model ini seorang jurnalis dituntut untuk mampu mencapai tingkatan multitasking. Akan tetapi Konvergensi media belum sepenuhnya didukung oleh seluruh awak Solopos di divisi redaksi.
\end{abstract}

Kata Kunci: Surat Kabar, Media, Konvergensi, Solopos

\begin{abstract}
Developments in communication technologies today is very rapidly. This development also affects the media industry. Media are required to adapt to the development of communication technology. The birth of digital media that uses Internet technology has affected the print media. A number of print media in the United States began to close because they can not compete with digital media. The print media is still survive are required to converge with preparing media-based digital media, one of them is Solopos.

This research is a qualitative descriptive study. Descriptive study by Whitney (in Nazir, 1988: 63) is the research to find facts with proper interpretation. The purpose of this study was to determine the model of media convergence carried Solopos as a response to the demands of the media industry that the newspaper should prepare to face the digital platform digital media continues to grow.

The results showed that the convergence of media that do Solopos an answer to the demands of the media industry that the newspaper should prepare to face the digital platform digital media continues to grow. The models that do Solopos media convergence is the convergence model of newsgathering in which this model of a journalist is required to achieve the level of multitasking.
\end{abstract}


However, media convergence has not been fully supported by the entire crew Solopos in the editorial division.

Keywords: Newspaper, Media, Convergence, Solopos

\section{A. Latar Belakang}

Perkembangan teknologi komunikasi mengalami perkembangan pesat dalam dua dasa warsa terakhir. Perkembangan teknologi yang demikian pesat itu juga merambah industri media. Media digital menjadi media yang sedang populer dalam beberapa tahun terakhir. Beberapa kalangan kemudian meramalkan media cetak bakal tergusur oleh teknologi media yang berbasis digital.

Chairman dan CEO News Corp Rupert Murdoch dalam berbagai kesempatan sering menyampaikan akhir era koran akibat kemunculan teknologi digital. Pada awal tahun 2000, dia memprediksi bahwa media cetak akan mati dalam 20 tahun ke depan. Dengan munculnya internet, surat kabar kertas akan digantikan berita digital di mana banyak pembaca akan beralih ke komputer tablet atau smartphone.

Di Amerika Serikat, lonceng kematian media cetak mulai terjadi kerena tidak mampu melawan perubahan atas berkembangnya teknologi informasi yakni media online. Contoh nyata adalah Newsweek. Majalah paling populer yang berumur 85 tahun berhenti cetak pada akhir 2012 dan kemudian berganti wajah menjadi media digital per Januari 2013. Sebelumnya pada 2009, The Rocky Mountain News memutuskan mengakhiri edisi cetak dan meninggalkan 117.600 pembacanya. The Seattle Post Intelligence yang sudah berusia 146 tahun juga bernasib sama. Revolusi teknologi informasi, seperti perkembangan internet juga mengganggu "kesehatan" koran besar di AS. The Washington Post yang sering menjadi kiblat koran dunia yang terpaksa harus memangkas sejumlah biaya dengan menutup sejumlah biro dan mengurangi jumlah karyawan mereka. (Kompas.com, 14 Oktober 2012)

Kematian koran mulai melanda Indonesia. Pada 2015, Sinar Harapan, Harian Bola dan Jakarta Globe menyatakan tutup. Mereka tidak mampu bertahan di industri media cetak karena gempuran media online.

Namun demikian, World Association of Newspapers and News Publishers (WANIFRA) dalam Kongres di Bali pada tahun 2012 menyatakan pertumbuhan industri surat kabar di Asia masih menjanjikan. Presiden WAN-IFRA Jacob Mathew dalam pembukaan Publish Asia 2012 di Bali mengatakan koran dianggap masih menjadi andalan bagi pelaku usaha media Asia. Keberadaan koran cetak masih sangat dibutuhkan di kawasan Asia. Tiga perempat dari 100 surat kabar terbesar di dunia terbit di Asia. Surat kabar menjadi sumber informasi primer. Meski demikian, Jacob mengingatkan bahwa tantangan yang dihadapi surat kabar di negara Barat juga akan dialami surat kabar di Asia, terutama pesatnya perkembangan media online. Beberapa negara Asia saat ini juga menjadi pusat pertumbuhan era digital dan teknologi. (Kompas.com, 12 April 2012).

Serikat Penerbit Surat Kabar (SPS) yang kini berganti nama menjadi Serikat Perusahaan Pers melakukan kajian agar media cetak bisa bertahan. Pada Kongres XXVII tahun 2007 di Jakarta, SPS menghasilkan beberapa rekomendasi. Rekomendasi itu di antaranya konvergensi media adalah sebuah keniscayaan yang mutlak perlu diantisipasi para pe- 
Diterbitkan oleh Program Studi Ilmu Komunikasi

Universitas Ahmad Dahlan Yogyakarta

nerbit media cetak melalui peningkatan sumber daya manusia perusahaan pers dalam penguasaan informasi dan teknologi. (Kompas, 15 November 2011)

Di Indonesia, ada beberapa media nasional yang telah merapkan konsep konvergensi antara lain di Grup Kompas Gramedia, Grup Tempo. Solopos sebagai koran daerah yang terbit di Solo pada 19 September 1997 juga berusaha menyesuaikan dengan perkembangan teknologi. Ancaman kematian koran sebagaimana disampaikan para pakar media sebagai efek atas derasnya media online diantisipasi dengan melakukan konvergensi media.

Pada 2004, Solopos membangun r Solopos FM. Selanjutnya, pada 2007, Solopos membuat Solopos.com. Pada 2014, Solopos mengembangkan televisi streaming yakni Solopos.tv. Dengan beberapa platform yang dimiliki tersebut, Solopos mencoba masuk tahap konvergensi. Adanya beberapa platform tersebut merupakan salah satu strategi dalam rangka mempertahankan eksistensi Solopos sebagai koran cetak dan sekaligus pengembangan unit usaha baru agar mampu bertahan dalam persaingan industri media.

\section{B. Masalah dan Tujuan Penelitian}

Berdasarkan latar belakang diatas, perumusan masalah dalam penelitian ini adalah bagaimana model konvergensi media yang dilakukan Solopos?

Adapun tujuan penelitian ini adalah untuk mengetahui bagaimana model konvergensi yang dilakukan Solopos, yang merupakan jawaban atas tuntutan industri media bahwa surat kabar harus mempersiapkan platform digital untuk menghadapi media digital yang terus tumbuh.

\section{Metode Penelitian}

Penelitian ini merupakan penelitian deskriptif kualitatif. Penelitian deskriptif menurut Whitney (dalam Nazir, 1988: 63) yaitu penelitian untuk mencari fakta dengan interpretasi yang tepat. Mempelajari masalah-masalah dalam masyarakat, serta tata cara masyarakat serta situasi-situasi tertentu, termasuk tentang hubungan kegiatan-kegiatan, sikap-sikap, pandangan-pandangan serta proses-proses yang sedang berlangsung dan pengaruhpengaruh dari suatu fenomena. Tujuan dari penelitian ini adalah untuk membuat deskripsi, gambaran atau lukisan secara sistematis, faktual dan akurat mengenai fakta-fakta, sifat-sifat serta hubungan antar fenomena yang diselidiki.

Teknik pengambilan informan melalui teknik purposive sampling (pengambilan informan berdasarkan tujuan). Sedangkan teknik pengumpulan data dilakukan dengan wawancara, dokumentasi dan studi pustaka.

Data dalam penelitian ini akan dianalisis secara kualitatif. Penelitian kualitatif merupakan suatu prosedur yang menghasilakan data deskriptif berupa kata tertulis, atau lisan orang-orang atau perilaku yang diamati (Moleong, 2001: 103).

Analisis data yang bersifat kualitatif mengharuskan peneliti untuk melakukan aktivitas secara serempak dengan pengumpulan data, interpretasi data dan menulis laporan pe- 
nelitian. (Creswell,2009: 145). Dengan demikian analisis data tidak dilakukan secara terpisah dengan pengumpulan data, tetapi merupakan kegiatan yang dilakukan bersama-sama. Selama pengumpulan data, peneliti bergerak secara interaktif dalam 3 komponen analisis yaitu reduksi data, sajian data dan simpulan akhir/verifikasi (Sutopo, 2002: 186).

\section{Hasil dan Pembahasan}

\section{Konsep Dasar Surat Kabar}

Menurut Onong Uchjana Effendy surat kabar adalah lembaran tercetak yang memuat laporan yang terjadi di masyarakat dengan ciri-ciri terbit secara periodik, bersifat umum, isinya termasa dan aktual mengenai apa saja dan dimana saja di seluruh dunia untuk diketahui pembaca" (Effendy,1993:241).

Secara lebih luas, surat kabar merupakan bagian dari pers. Menurut Harimurti $(1984 ; 95)$ pers adalah media massa yang merupakan media cetak, merupakan terbitan yang memuat berita, risalah karya, iklan dan lain-lain. Secara harfiah pers berarti cetak dan secara tercetak atau publikasi secara dicetak atau printed publications. (Effendy, 2001; 145). Secara singkat pengertian pers menurut Kurniawan Junaedhie $(1991 ; 205)$ adalah sebutan bagi penerbit/perusahaan/kalangan yang berkaitan dengan media massa atau wartawan.

Berdasarkan UU Nomor 40 Tahun 1999 tentang Pers disebutkan bahwa Pers adalah lembaga sosial dan wahana komunikasi massa yang melaksanakan kegiatan jurnalistik yang meliputi mencari, memperoleh, memiliki, menyimpan, mengolah, dan menyampaikan in-formasi baik dalam bentuk tulisan, suara, gambar, suara dan gambar, serta data dan grafik maupun dalam bentuk lainnya dengan menggunakan media cetak, media elektronik, dan segala jenis saluran yang tersedia.

\section{Konsep Dasar Konvergensi Media}

Konvergensi media merupakan salah satu perkembangan media massa yang melibatkan banyak faktor teknologi di dalamnya. Kehadiran internet mendorong media massa menerapkan konsep konvergensi media seperti media online, e-paper, e-books, radio streaming, media sosial, yang digabungkan dengan media lainnya.

Terry Flew dalam An Introduction to New Media menyatakan konvergensi media merupakan hasil dari irisan tiga unsur new media yaitu jaringan komunikasi, teknologi informasi, dan konten media. Konvergensi media mengusung pada konsep penyatuan berbagai layanan informasi dalam satu piranti informasi membuat satu gebrakan digitalisasi yang tidak bisa dibendung lagi arus informasinya. Konvergensi menyebabkan perubahan radikal dalam penanganan, penyediaan, distribusi dan pemrosesan seluruh bentuk informasi baik visual, audio, data dan sebagainya (Preston, 2001).

Menurut Fiddler (2003: 29) terjadinya konvergensi media juga didukung oleh berbagai hal seperti kekuatan-kekuatan ekonomi, politik, dan sosial yang memainkan peran besar dalam penciptaaan teknologi-teknologi baru; berbagai penemuan dan inovasi tidak diadopsi secara luas lantaran keterbatasan teknologi itu sendiri; dan adanya kesempatan dan alasan ekonomi, sosial, dan politik yang mendorong perkembangan teknologi baru. 
Diterbitkan oleh Program Studi Ilmu Komunikasi

Universitas Ahmad Dahlan Yogyakarta

Konvergensi industri media dan teknologi digital mengarah pada bentuk-bentuk yang dikenal sebagai komunikasi multimedia. Multimedia atau dikenal juga sebagai media campuran, pada umumnya didefinisikan sebagai medium yang mengintegrasikan dua bentuk komunikasi atau lebih (Fiddler, 2003:39). Fiddler (2003) menyatakan kehadiran konvergensi media sebagai salah satu bentuk mediamorfosis yaitu suatu transformasi media komunikasi yang biasanya ditimbulkan akibat hubungan timbal balik yang rumit antara berbagai kebutuhan yang dirasakan, tekanan persaingan dan politik, serta berbagai inovasi sosial dan teknologi.

Adopsi teknologi digital oleh perusahaan media massa dalam melahirkan konvergensi media didukung oleh faktor tekanan dalam bisnis media massa. Kini para perusahaan media massa berlomba-lomba menganut konvergensi.

Jenkins (2006:10) menuliskan, pada awal tahun 1983 Ithiel de Sola Pool dalam bukunya berjudul Technology of Freedom telah menggunakan istilah konvergensi untuk menggambarkan kekuatan perubahan dalam industri media. Komunikasi massa (pers, radio, televisi). Perangkat fisik tunggal seperti kabel dan gelombang udara, yang pada masa lalu dalam bentuk terpisah, kini dapat diakomodasi oleh satu medium seperti penyiaran, pers, dan komunikasi lewat telepon. A process called "a covergence modes" is blurring the media, even between point-to-point communications, such as the post, telephone and telegraph, and mass communications, such as the press, radio, and television. A single physical means-be it wires, cables or airwaves-may carry services that in the past were provided in separate ways. Conversely, a service that in the past was provided by any one medium-be it broadcasting, the press, or telephony-can now be provided in several different physical ways. So the one-to-one relationship that used to exist between a medium and its use is eroding.(Pool 1983:23 (Jenkins, 2006:10)

Transformasi media cetak ke arah konvergensi dapat mengadopsi jenis konvergensi yang dikemukakan oleh Grant (2009:33). Konvergensi jurnalistik mensyaratkan perubahan cara berpikir media tentang berita dan peliputannya. Bagaimana media memproduksi berita dan bagaimana media menyampaikan berita kepada khalayaknya. Namun, praktik konvergensi saat ini masih sebatas pada cara menyampaikan berita melalui platform yang berbeda yaitu media cetak, penyiaran, dan online.

Dalam konvergensi jurnalistik dikenal adanya tiga model menurut Grant, yaitu konvergensi newsroom, konvergensi newsgathering, dan konvergensi konten.

1. Konvergensi newsroom. Dalam konvergensi ini jurnalis yang berbeda platform, misalnya dari surat kabar, online, dan televisi menyatukan dirinya dalam satu ruang produksi berita. Mereka mengerjakan tugas sesuai dengan platform medianya.

2. Konvergensi newsgathering. Dalam menjalankan model ini, seorang jurnalis dituntut untuk mampu mencapai tingkatan multitasking. Dengan melalui pelatihan atau training khusus, seorang jurnalis dituntut untuk dapat melakukan pekerjaan yang dilakukan oleh media dengan platform lain dalam satu grup. Misalnya, seorang wartawan cetak harus mampu membuat berita untuk cetak, online, dan sekaligus untuk televisi. Selain itu juga dituntut untuk mengambil foto atau video.

3. Konvergensi content. Berita akhirnya disuguhkan dalam bentuk multimedia, yang merupakan kombinasi antara teks, gambar, audio, video, blog, podcasts, atau slide show. Pilihannya terus berkembang. Saat ini, konvergensi isi masih sangat muda atau baru dimulai. Namun, kita dapat mengintip masa depan melalui website yang inovatif. Bayangkan beberapa tahun ke depan medium hybrid baru mengkombinasikan antara 
audio dan video tv, sifat responsif dan sumber dari website, kemudahan dibawa dan kualitas cetak dari koran. Editor dan reporter akan menjadi content producer yang dilatih untuk memilih cerita mana yang paling efektif, teknik yang paling menghibur dari menu biasa hingga pilihan multimedia.

Teknologi informasi dan komunikasi yang semakin pesat pada abad ke-20 membuat wajah media massa berubah total. Jika semula beberapa pemilik media hanya memiliki satu platform, di era sekarang ini pemilik media bisa memiliki beberapa platform. Jika pemilik media semula memiliki platform cetak, kini pada awal tahun 2000 mulai dikembangkan ke platform lain seperti cetak dan online, cetak dan radio, cetak dan televisi atau malah cetak, online dan televisi.

Begitu juga dengan yang dilakukan oleh Solopos. Pemimpin Redaksi Solopos Suwarmin mengatakan Solopos berdiri pada 19 September 1997. Sejak 2004, Solopos melakukan diversifikasi produk. Diversifikasi ini merupakan bentuk penganekaragaman usaha. Pada tahun 2004 memiliki stasiun radio Solopos FM dan pada 2007 membikin portal berita Solopos.com. Kemudian pada 2014, Solopos membuat televisi streaming atau televisi berbasis digital yakni Solopos.tv.

Dari uraian tersebut Solopos sudah melakukan diversifikasi produk dan mengikuti tren media saat ini yang mulai mempersiapkan format digital. Diversivikasi dimaksudkan untuk memaksimalkan potensi yang ada di Solopos yang merupakan pelaku industri media. Solopos melakukan diversifikasi produk dengan menciptakan platform-platform baru dengan menyesuaikan dengan teknologi yang ada. Pilihan diversifikasi merupakan salah satu cara agar media mampu bersaing dalam industri media. Upaya Solopos melebarkan sayap di bidang media ini merupakan lah yang sering disebut dengan konvergensi. Konvergensi media merupakan upaya mengembangkan usaha dengan bidang yang sama namun berbeda jenis.

Solopos sebagai koran lokal dan sekaligus market leader di Soloraya, Solopos juga menyadari tentang ada perubahan di industri media. Mantan Pemimpin Redaksi Solopos Adhitya Noviardi mengatakan industri media saat ini mengalami perubahan seiring dengan perkembangan teknologi informasi. Maka dari itu, Solopos mau tidak mau harus berubah menyesuaikan dengan situasi dan kondisi saat ini. Solopos harus mangkombinasikan kekuatan-kekuatan media yang dimiliki baik cetak, online, radio dan televisi streaming.

Dengan adanya beberapa platform tersebut, Solopos telah mempersiapkan mediamedia dalam rangka menuju konvergensi sejak dini. Menurut Adhitya, media baru tersebut dipersiapkan sejak dini meskipun era digital di Indonesia khususnya di daerah belum tumbuh seperti di negara-negara maju. Platform cetak di Solopos tetap dipertahankan dan terus ditingkatkan oplah dan pendapatan iklannya. Sementara online juga harus dipersiapkan sejak dini dan sebisa mungkin mendatangkan penghasilan. Selanjutnya pengelolaannya dikombinasikan oleh masing-masing platform tersebut. Dengan strategi tersebut, jika suatu saat era cetak mulai redup, maka online langsung bisa menggantikan.

Menurut Adhitya, konvergensi media merupakan pilihan yang harus diambil oleh media baik media cetak maupun televisi. Media massa harus mampu menyesuaikan dengan perkembangan zaman khususnya di tengah persaingan industri media yang semakin kompetitif. Jika tidak mampu menyesuaikan, maka media tersebut bakal ditinggalkan audiens. 
Diterbitkan oleh Program Studi Ilmu Komunikasi

Universitas Ahmad Dahlan Yogyakarta

Dari uraian tersebut, sudah ada kesadaran dari seluruh stakeholders yang ada di Solopos bahwa media saat ini telah berubah. Pengelolaan dan cara kerja juga harus berubah. Sebab, konvergensi media telah menuntut cara kerja orang-orang media, termasuk tim redaksi Solopos berubah. Kecepatan kerja dalam memproduksi berita menjadi sebuah kebutuhan. Para penghasil berita dituntut harus profesional, dan memiliki loyalitas tinggi. Pekerja media dalam bekerja di era konvergensi bisa untuk beberapa platform. Berita yang ditulis oleh wartawan kini tidak lagi cuma dimuat di satu media, tetapi bisa untuk beberapa media dari beberapa platfom.

Redaktur Pelaksana Solopos.com Rini Yustiningsih mengatakan konvergensi yang dilakukan reporter tahap pertama dilakukan antara Solopos dengan Radio Solopos FM. Para repoter diminta untuk melaporkan ke Solopos FM jika meliput suatu peristiwa. Tim Solopos FM akan menghubungi reporter Solopos melalui sambungan telepon untuk diminta melaporkan secara langsung tentang peristiwa yang terjadi atau live report.

Tahap kedua, antara Solopos FM, Solopos, dan Solopos.com pada 2007. Konsep ini dintensifkan pada 2012. Selain diminta untuk melakukan live report untuk radio, para reporter yang ada di lapangan juga diminta menulis secara langsung berita yang didapatkannya. Berita yang dikirim langsung tersebut selanjutnya akan digunakan untuk Solopos.com saat itu juga. Tahap ketiga dengan melibatkan Solopos, Solopos FM, Solopos.com dan Solopos.tv. Para reporter Solopos yangh ditunjuk juga diminta mengirimkan video untuk bahan di Solopos.tv.

Dengan melibatkan empat platform tersebut, reporter dituntut untuk mengubah cara kerjanya. Seorang reporter tidak hanya bekerja untuk satu media yakni Solopos, tetapi juga untuk Solopos.com, Solopos.tv dan juga radio. Bagan berikut ini merupakan cara kerja reporter Solopos dalam konvergensi media.

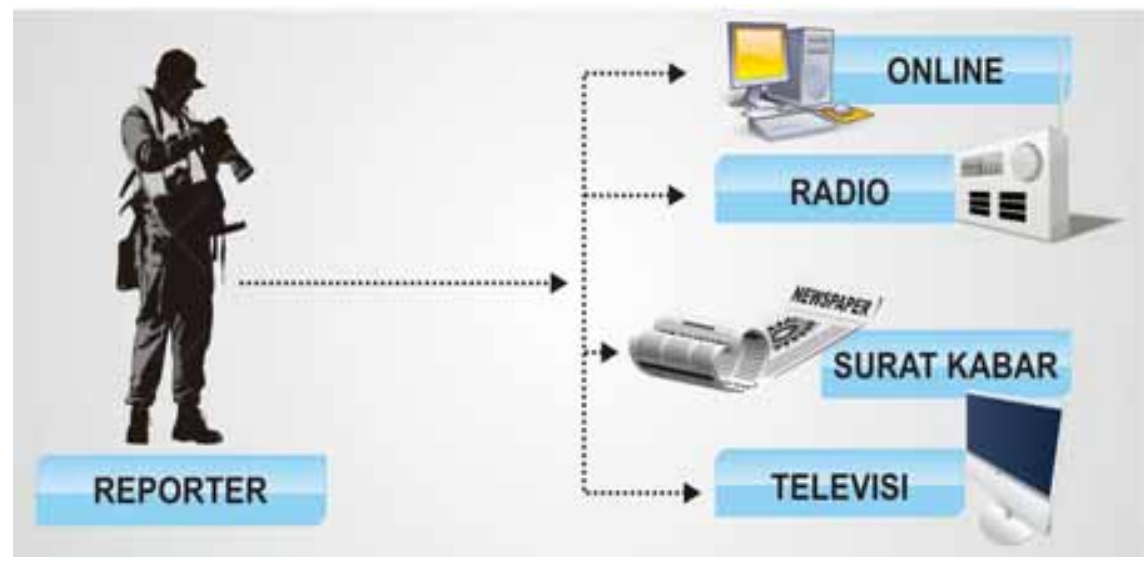

\section{Gambar 1. Cara kerja reporter Solopos dalam konvergensi media}

Dari uraian di atas, jika para reporter bisa menjalankan cara kerja untuk seluruh platform yang ada, maka konvergensi media di Solopos akan berjalan dengan baik. Namun, jika reporter tidak bisa mensuport platform-platform yang ada, maka konvergensi media di 
Solopos tidak akan berjalan maksimal. Hal itulah yang menjadi tantangan manajemen Solopos untuk memaksimalkan pola kerja para reporter untuk bekerja dalam beberapa platform.

Menurut Redaktur Pelaksana Solopos.com, untuk mendukung konvergensi media, maka pola pengiriman berita mengalami perubahan. Reporter yang semula mengirim berita ke masing-masing redaktur atau folder sesuai rubrik, maka reporter diwajibkan mengirim berita ke newsroom@solopos.co.id. Berikut ini bagan atau alur pengiriman materi dari reporter ke newsroom:

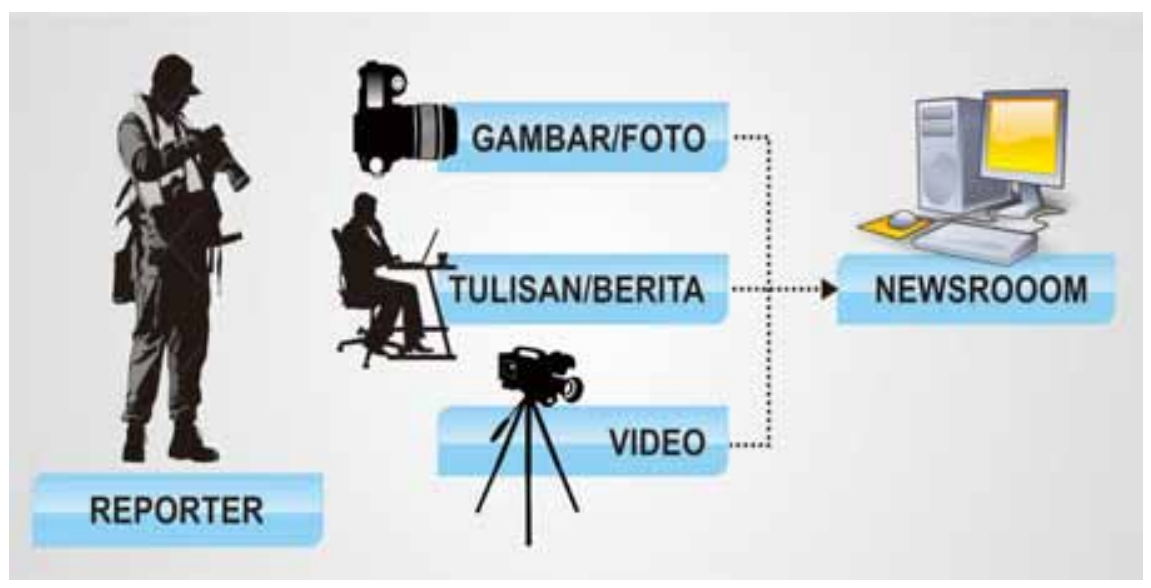

Gambar 2. Alur pengiriman materi dari reporter ke newsroom

Dengan tersentralnya materi berita dari reporter ke newsroom, semua platform baik pengelola cetak, online, radio dan televisi bisa langsung mengakses ke newsroom. Dengan demikian, sistem itu akan memudahkan proses kerja. Berikut ini bagan atau alur pengambilan materi berita dari newsroom:

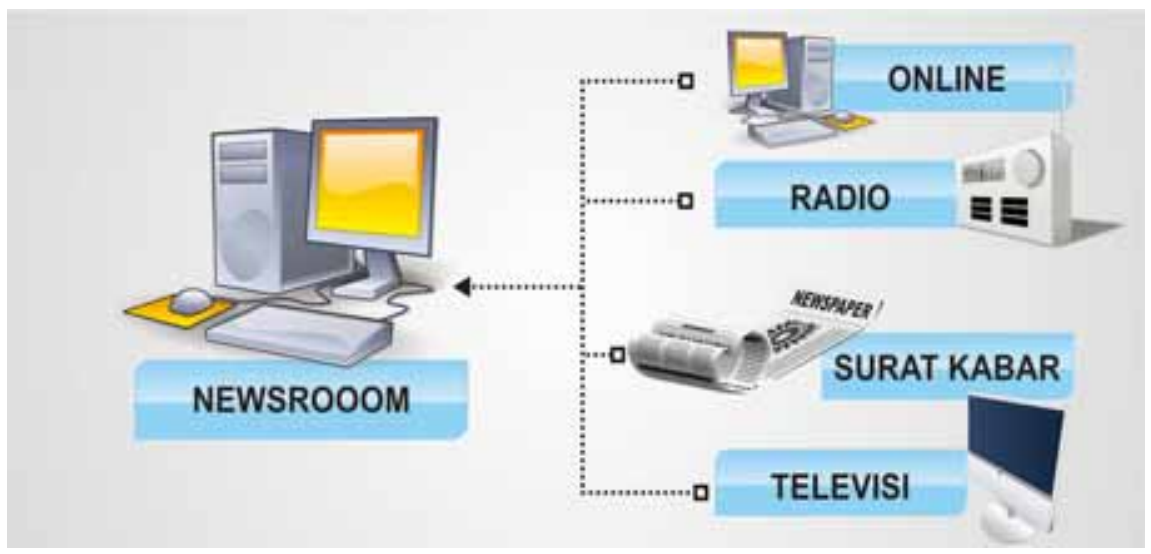

Gambar 3. Alur pengambilan materi berita dari newsroom 
Diterbitkan oleh Program Studi Ilmu Komunikasi

Universitas Ahmad Dahlan Yogyakarta

Dari alur tersebut, konvergensi yang dilakukan di Solopos masuk pada model konvergensi newsgathering di mana dalam model ini, seorang jurnalis dituntut untuk mampu mencapai tingkatan multitasking. Dengan melalui pelatihan atau training khusus, seorang jurnalis dituntut untuk dapat melakukan pekerjaan yang dilakukan oleh media dengan platform lain dalam satu grup.

Semua reporter di Solopos dituntut bekerja untuk beberapa platform. Perubahan pola kerja ini diakui oleh Reporter Ekonomi Bisnis Shoqib Agriawan. Dia mengakui para reporter Solopos dituntut bekerja untuk beberapa platform atau media. Kondisi itu mau tidak mau telah merubah pola kerja para reporter. Jika sebelumnya hanya bekerja untuk cetak, reporter dituntut bekerja untuk online, televisi dan radio.

Shoqib mengakui dengan bekerja untuk empat media yakni Solopos, Solopos.com, Solopos.tv dan Solopos FM merupakan tantangan bagi para reporter untuk bisa melaksanakan tugas itu secara baik. Bahkan, jika hal tersebut bisa dilaksanakan maka akan membikin reporter semakin tangguh karena bisa bekerja untuk beberapa jenis platform. Namun, Shoqib mengakui beban kerja yang begitu banyak bisa menjadikan kinerja tidak maksimal. Sebab, pada saat yang bersamaa reporter dituntut untuk cepat menyampaikan berita ke online, mengambil gambar dan melakukan live report untuk radio. Persoalan waktu menjadi kendala dalam menjalankan keempat platform ini.

Redaktur Pelaksana Solopos.com Rini Yustiningsih mengakui dari seluruh reporter Solopos sudah mengirimkan hasil liputan ke newsroom. Ada reporter yang sudah menjalankan tugas dengan baik untuk mendukung konvergensi, namun ada yang belum. Artinya, ada reporter bekerja untuk beberapa platform seperti cetak, online, radio dan televisi. Kasus terbakarnya hutan di Gunung Lawu merupakan contoh penerapan konvergensi yang bagus. Pada saat kejadian, reporter selalu memberikan up date atau laporan berita ke newsroom dan mengirimkan video yang bisa digunakan untuk Solopos.tv.

Namun, ada juga reporter yang mindset kerjanya masih untuk cetak dan belum menjalankan prinsip online first. Ketika reporter melakukan liputan, berita yang didapatkan seharusnya dikirim pada saat itu juga, namun baru dikirim ke newsroom beberapa jam kemudian. Kasus kecelakaan di Klaten pada bulan November yang terjadi pukul 05.00 WIB. Namun, reporter baru mengirimkan berita pada pukul 18.00 WIB. Budaya kerja cetak juga masih dimiliki beberapa reporter Solopos di mana ketika mengirimkan berita dengan format cetak dan tim di online Solopos kemudian menyusun berita itu dengan format online.

Dari keterangan tersebut diketahui bahwa belum seluruh awak yang ada di Solopos menjalankan instruksi yang diinstruksikan manajemen bahwa setiap reporter yang ada harus berkontribusi untuk beberapa platform. Budaya kerja untuk cetak masih dilakukan oleh sejumlah reporter Solopos. Sebagian reporter belum bekerja dengan konsep online first untuk mendukung Solopos.com.

Shoqib mengakui jika bekerja untuk beberapa media cukup menambah beban bagi reporter. Namun, dengan adanya tambahan beban tersebut diharapkan perusahaan bisa memberikan penghargaan khusus berupa insentif atau tunjangan khusus maupun bonus.

Untuk mendukung konvergensi khususnya untuk Solopos.tv, sepuluh reporter Solopos dibekali dengan tablet yang bisa digunakan untuk merekam gambar dan sekaligus menulis berita. Sementara, sebagian reporter juga dibekali dengan laptop dan modem. 
Dengan tablet tersebut, reporter bisa merekam gambar dan kemudian menulis, serta selanjutnya mengirimkannya ke newsroom. Sedangkan untuk live report petugas yang ada di Solopos FM bisa menghubungi reporter secara yang langsung yang pada saat itu berapa di lokasi liputan. Dengan adanya laportop dan modem diharapkan reporter bisa menulis dengan cepat dan selanjutnya mengirimkannya ke newsroom.

Reporter Ekonomi Bisnis Shoqib Agriawan mengatakan untuk hal-hal tertentu peranti yang diberikan oleh manajemen Solopos sudah dianggap cukup mendukung kinerja. Namun, untuk pada situasi tertentu tidak bisa maksimal dalam mendukung kinerja. Sebab, tablet yang diberikan tidak bisa berfungsi secara optimal jika untuk melakukan liputan malam hari.

Dari uraian tersebut, peran teknologi sangat berpengaruh dalam mendukung penerapan konvergensi media. Konvergensi media membutuhkan dukungan teknologi yang memadai sehingga bisa menghasilkan produk yang baik dan berkualitas. Dengan teknologi yang mendukung, para pekerja media yang melaksanakan konvergensi tidak akan terganggu dalam bekerja.

\section{E. Penutup}

\section{Kesimpulan}

a. Konvergensi media yang dilakukan Solopos merupakan jawaban atas tuntutan industri media bahwa surat kabar harus mempersiapkan platform digital untuk menghadapi media digital yang terus tumbuh.

b. Model Konvergensi yang dilakukan di Solopos adalah model konvergensi newsgathering di mana dalam model ini seorang jurnalis dituntut untuk mampu mencapai tingkatan multitasking yaitu satu reporter bekerja untuk beberapa media atau beberapa platform dalam satu grup.

c. Konvergensi media belum sepenuhnya didukung oleh seluruh awak Solopos di divisi redaksi. Konsep satu reporter bekerja untuk beberapa platform baru dilaksanakan oleh sebagian awak Solopos yang bekerja untuk cetak, online, televisi dan radio untuk mendukung konvergensi media.

d. Adanya beban kerja untuk beberapa platform belum diimbangi dengan pemberian penghargaan khusus berupa materi kepada para awak redaksi yang terlibat dalam mendukung konvergensi media.

e. Teknologi memiliki peran yang sangat penting dalam mendukung konvergensi media. Reporter belum dibekali dengan peralatan yang mendukung kinerja dalam segala situasi.

\section{Saran}

a. Manajemen Solopos harus terus mengkomunikasikan kepada jajaran redaksi agar awak redaksi mensupport program konvergensi media bahwa reporter harus bisa bekerja untuk beberapa media. Konvergensi media adalah suatu keharusan agar mampu bersaing di tengah agresifnya media digital. Konsep online first harus diingatkan 
Diterbitkan oleh Program Studi Ilmu Komunikasi

Universitas Ahmad Dahlan Yogyakarta

kembali ke seluruh awak redaksi sehingga mindset bekerja untuk cetak bisa ditinggalkan.

b. Manajemen Solopos perlu memikirkan penghargaan khususnya yang berupa materi seperti bonus atau tunjangan kepada pihak-pihak yang telah berkontribusi aktif dalam bekerja untuk beberapa platform yang ada di Solopos. Dengan langkah itu para reporter akan lebih bersemangat dan tertantang untuk bekerja di beberapa platform tersebut.

c. Manajemen Solopos perlu melengkapi reporter dengan peralatan dan teknologi yang mendukung tugas reporter di lapangan. Dengan teknologi yang memadai maka konvergensi media akan berjalan dengan lancar. 


\section{Daftar Pustaka}

August E Grant. \& JS. Wilkinson. 2009. Understanding Media Convergence: The State of the Field. New York: Oxford University Press.

Cresswell, J.W. 2009. Research Design: Pendekatan Kualitatif, Kuantitatif and Mixed.EdisiKetiga. Pustaka Pelajar.Yogyakarta.

Effendy, Onong Uchjana. 1993. Ilmu, Teori dan Filsafat Komunikasi. Bandung: PT Citra Aditya Bakti

Effendy, Onong Uchjana.2001. Ilmu Komunikasi Teori dan Praktek. Bandung: PT. Remaja Rosdakarya

Flew, Terry. 2002. New Media: an Introduction. Melbourne: Oxford University Press.

Harimurti Kridalaksana, 1984. Leksikon Komunikasi. Jakarta: Pradya Paramita.

Henry Jenkins. 2006. Convergence Culture, Where Old and New Media Collide. New York: New York University Press.

Kurniawan Junaedhie. 1991. Ensiklopedia Pers Indonesia. Jakarta: Gramedia Pustaka Utama.

Moleong J, Lexy. 2001. Metodologi Penelitian Kualitatif. Remaja Rosdakarya. Bandung Nazir, Muhammad.1988. Metode Penelitian. Ghalia. Jakarta.

Paschal Preston. 2001. Reshaping Communications. London: Thousand Oaks, Calif: Sage. Roger Fidler. 2003. Mediamorfosis. Yogyakarta: Bentang.

Sutopo, HB. 2006. Metodologi Penelitian Kualitatif Dasar Teori dan Terapannya

Dalam Penelitian, Universitas Sebelas Maret Press, Surakarta.

\section{Wawancara:}

- Suwarmin, Pemimpin Redaksi Solopos

- Adhitya Noviardi, Mantan Pemimpin Redaksi Solopos

- Rini Yustiningsih, Redaktur Pelaksana Solopos.com

- Shiqib Agriawan, Reporter Ekonomi Bisnis

\section{Sumber Lain}

http://internasional.kompas.com/read/2012/10/14/11305041/Koran.Dunia.

Tak.Ingin.Mati.Gaya. Diakses pukul 13.30 WIB

http://sains.kompas.com/read/2012/04/12/06221630/contact.html. Diakses pukul 20.15 WIB.

http://www.kpi.go.id/download/regulasi/UU\%20No.\%2040\%20Tahun\%20 1999\%20tentang\%20Pers.pdf. Diakses pada 2 Januari 2015 pukul 13.45 WIB 